\title{
CLINICAL AND RADIOGRAPHIC EVALUATION OF SOFT-LINER ATTACHMENT FOR BAR/IMPLANT RETAINED MAXILLARY OVERDENTURES. A ONE YEAR PROSPECTIVE STUDY
}

\author{
Dina Bahgat El Talawy* and Dina Bahgat El Talawy*
}

\begin{abstract}
Aim of the study: This study aimed to evaluate clinical and radiographic outcome of soft-liner attachment for bar/implant retained maxillary overdentures after one year.

Materials and methods: Six completely edentulous patients (3 males and 3 females) complained from lack of stability and insufficient retention of their maxillary dentures received 4 implants in the anterior part of the maxilla (2 at canine areas and 2 at 2nd premolar areas) using the standardized two-stage submerged surgical protocol. Six months after surgery, implants were connected with a resilient bar with 2 short distal cantilevers of $7 \mathrm{~mm}$ length. The fitting surfaces of maxillary dentures were lined with auto polymerized addition silicone resilient liner which is used as a female housing over the bar using closed mouth technique. Plaque Index (PI), Bleeding Index (BI), and Gingival Index (GI), Probing depth (PD), Implant stability (ISQ) and Marginal bone loss (MBL) were evaluated at time of overdenture insertion T0, 6 months after overdenture insertion (T6) and 12 months after overdenture insertion (T12).
\end{abstract}

Results: None of the implants failed after one year follow-up resulted in $100 \%$ survival rate. There was no significant difference in PI, GI, BI between observation times. Both PD and MBL increased significantly with time. ISQ decreased significantly at T6 and increased again at T12. There was a significant positive correlation between MBL and PD only.

Conclusion: Soft liner attachments for cantilevered bar-implant retained maxillary overdentures are associated with good peri-implant soft tissue health, good implant stability and minimal marginal bone loss after one year.

KEY WORDS: Soft-liner attachment, Bar, Maxillary, Implant overdenture

\section{INTRODUCTION}

Maxillary implant overdentures are indicated in the following cases: High lip-line, severely resorbed maxillae, long teeth, need of facial support, buccal inclined ridge, intermaxillary distance $>15 \mathrm{~mm}$, skeletal class III, crossbite, thin mobile mucosa, insufficient lip support, and incongruence of implant location $^{(1,2)}$. Unlike mandibular overdentures,

* Lecturer, Department of Removable Prosthodontics, College of Oral and Dental Surgery, Misr University For Science and Technology, Egypt. 
treatment of the edentulous maxilla by implantsupported overdentures is challenging and complicated by inherent problems, such as reduced bone quality and quantity, divergent implant axes, and offset positioning of denture teeth, which increase bending moments on implants..$^{(3,4)}$

Various attachment types can be employed for maxillary overdentures, basically splinting (bar-clip constructions with various bar-shape designs) or not splinting the implants (various ball type attachments, magnet attachments, Locators and attachments with telescopic copings) $)^{(5)}$. A minimum of four wellspaced implants, evenly distributed over the arch and connected by a bar, will enhance the stability of the maxillary overdenture. The implants are mostly located in the anterior part of the upper jaw, between the premolars, thus avoid sinus floor elevation ${ }^{(6,7)}$. However, the main disadvantages of bars and clips are rapid wear, limited rotational freedom, bulk and soft tissue proliferation in unobturated regions under the $\operatorname{bar}^{(8)}$.

Several authors reported the use of silicon soft liner as female housings instead of clips over the bar attachments of implant retained mandibular overdentures ${ }^{(8-11)}$. Soft liners as an attachment for overdenture bars have several advantages including resistance to wear, obturation of the space under the bar, absorption and distribution of chewing forces to the implants and edentulous ridge and freedom of denture movement ${ }^{(8,12)}$. Moreover these liners offer more retention, which even when diminished after multiple insertions, was still greater than with bars and clips ${ }^{(13)}$.

Soft liner-retained mandibular overdentures to 2 implants connected with bars had comparable patient satisfaction, less prosthetic maintenance and costs, and less soft tissue complications when compared to clip-retained ones after 3 years ${ }^{(9)}$. Also soft liner attachments for bar-implant retained mandibular overdentures are associated with decreased resorption and flabbiness of maxillary anterior residual ridge and fewer maxillary denture relining times when compared to clip attachments. In a one year randomized controlled clinical trial, Elsyad and ElShoukouki (10) favorable clinical and radiographic peri-implant tissue responses to resilient liner attachment when compared to clip attachments of bar-two implant retained mandibular overdenture. Unfortunately, the effect of soft liner attachments for bars of maxillary or even mandibular overdentures supported by four implants was not investigated yet. The space provided around the bars in the fitting surface of 4-implant supported overdentures is greater than those provided in implant retained overdentures with 2 implants only. These spaces become evident for maxillary overdentures to provide more freedom of insertion and removal of the dentures over the long bar superstructure since the implants are usually angled labially. Accordingly, the aim of the present investigation was to evaluate peri-implant soft tissue health with soft-liner attachments for bar/ implant retained maxillary overdentures after one year.

\section{MATERIALS AND METHODS}

\section{Patients}

Six completely edentulous patients (3 males and 3 females) with mean age of 57.2 years were selected from the outpatient clinic of Prosthodontic Department, College of Oral and Dental Surgery, Misr University For Science and Technology, Egypt. All patients complained from lack of stability and insufficient retention of their maxillary dentures. Inclusion criteria were: 1) adequate width and height of maxillary ridge bone for the placement of 4 implants, 2) adequate inter-arch space (at least 15 $\mathrm{mm}$ from the occlusal plane to the crest of maxillary ridge to allow for bar construction(6)), 3) good oral hygiene. Exclusion criteria included one or more of the following conditions; diabetes, smoking habit, osteoporosis, immune deficiency, radiotherapy 
to the head and neck region and anticoagulant therapy. The patients involved in the study provided an informed consent before the treatment were informed and accepted to be included in the study. The study was conducted according to principles stated in the Helsinki Declaration.

\section{Surgical and prosthetic procedures}

For each patient, the existing maxillary denture was duplicated using heat cure clear acrylic resin. Metal balls of known length and diameter were attached to the duplicate denture at proposed implant sites (2canines and 2 second premolars ${ }^{(6,7)}$ ) to be used as a radiographic template. A preoperative panoramic radiograph was taken to evaluate implant positions, anatomical boundaries of maxillary sinus and select correct implant length. The radiographic template was then converted to surgical template by attaching 4 metal cylindrical tubes at implant positions.

Four tapered dental implants (TioLogic, Dentaurum, Germany) were placed, in the anterior part of the maxilla (2 at canine areas and 2 at 2 nd premolar areas) using the standardized two-stage submerged surgical protocol. Distribution of implant lengths and diameters are presented in table 1. All surgeries were carried out under local anesthesia and antibiotic cover ( $2 \mathrm{~g}$ of amoxicillin 1 hour before surgery) by the same oral and maxillofacial surgeon without using any bone grafting procedures. A crestal incision in the maxilla was made between right and left first molar areas. The mucoperiosteum was elevated and the bone gently drilled to prepare osteotomy sites for the implants. The insertion torques $\geq 35 \mathrm{Ncm}$ were achieved for all implants. With reduced bone quality osteotomy preparation was not allowed to reach the final drill, instead the drill before the final drill was used as the last drill to obtain sufficient primary stability. Three weeks postoperatively, the patient's existing maxillary dentures were relieved over implant sites and refitted to the mucosa using a tissue conditioner (Viscogel,
DeTrey/Dentsply) after total closure of the wound. Six months after surgery, the healing abutments (selected according to the mucosal thickness) were threaded in the internal hex of the implants.

TABLE (1) Distribution of implant lengths and diameters

\begin{tabular}{|c|c|c|c|c|}
\hline \multirow{2}{*}{ Implant diameter } & \multicolumn{4}{|c|}{ Implant length } \\
\cline { 2 - 5 } & $15 \mathrm{~mm}$ & $13 \mathrm{~mm}$ & $11 \mathrm{~mm}$ & $9 \mathrm{~mm}$ \\
\hline $\mathbf{3 . 7 m m}$ & 6 & 2 & 0 & 0 \\
\hline $\mathbf{4 . 2} \mathrm{mm}$ & 7 & 5 & 2 & 2 \\
\hline
\end{tabular}

Two weeks later, new maxillary and mandibular dentures were constructed to each patient. Preliminary maxillary and mandibular impressions were made. Custom trays were fabricated (maxillary tray was fabricated with holes over the implants) using autopolymerized acrylic resin (GC, GC United Kingdom Ltd. Newport Pagnell, UK.) and molded with plastic impression compound (Impression Compound, Kerr Italia S.pA, Salerno, Italy). Functional impression for maxillary and mandibular ridges was completed with zinc oxide eugenol paste (Cavex Outline; Cavex Holland BV) using finger pressure. The maxillary tray was removed from the mouth; excess impression material was cleaned from open areas. Long impression copings were threaded to the implants (fig.1). Light-body rubber base material (Speedex, Coltene/ Whaledent Inc,

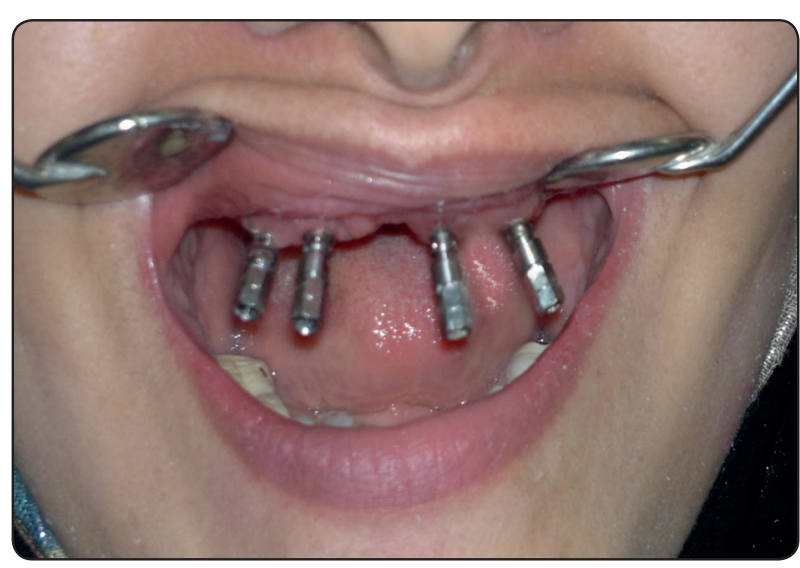

Fig. (1) Long impression copings threaded to the implants intraorally. 
Cuyahoga Falls, Ohio) was injected around the impression copings while applying finger pressure to the tray.

The transfer copings were picked up to the polished surface of the tray with autopolymerizing acrylic resin. Implant analogues were attached to the impression copying with the long fixation screws and the final impressions were poured with extrahard stone (ZETA, Orthodontic Stone; WhipMix. Corp, Louisville, Ky). Bar abutments (TioLogic, Dentaurum, Germany) were selected according to the mucosal thickness and threaded into the implant analogues in the maxillary cast. The plastic pattern of a resilient bar (OT bar multiuse ${ }^{\circledR}$, RHEIN 83, Italy) was luted to the plastic portions of bar abutments leaving $2 \mathrm{~mm}$ clearance space between the bar and the ridge. Two $7 \mathrm{~mm}$ distal cantilevers were added to the bar according to the recommendation of a previous study ${ }^{(14)}$ (fig.2). The bar assembly was invested, casted and tried in patient mouth using Sheffield test was to verify the passive fit of the bars. If the passive fit was not obtained, the bar was sectioned and soldered.

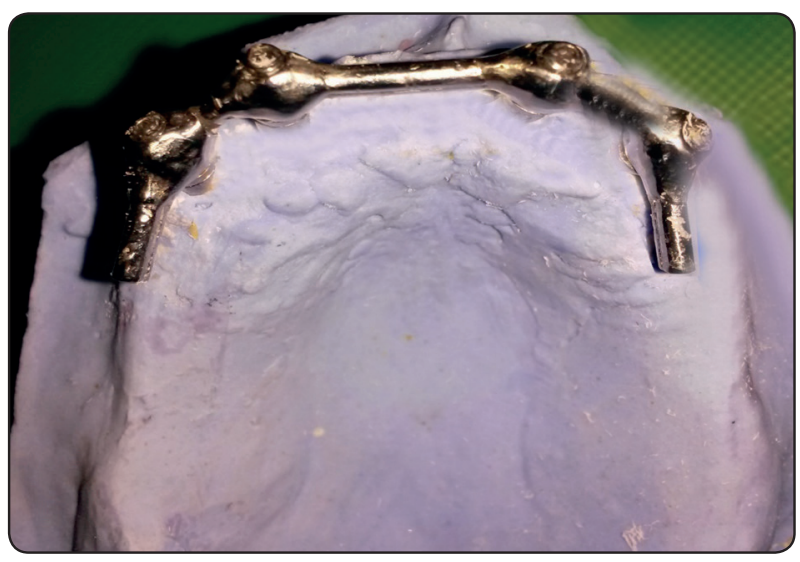

Fig. (2) The bar assembly with the 2 short distal cantilevers on the cast.

Jaw relation was recorded and semi anatomic acrylic teeth (Vitapan ${ }^{\circledR}$,Vita Zahnfabrik, Bad Säckingen, Germany) were arranged using balanced occlusion concept. Silicon indices ${ }^{(8)}$ were made over the maxillary trial dentures to ensure that the space between the bar and the teeth was enough for resilient liner and acrylic resin. Aluminum foil sheets of $2 \mathrm{~mm}$ thickness ${ }^{(10)}$ were applied over the bars to provide space for resilient liner, and dentures were processed. The bar was screwed to the bar abutments intraorally at $25 \mathrm{Ncm}$ toque. The spaces under the bars were blocked out intraorally with wax. The fitting surfaces of maxillary dentures were painted with soft liner adhesive and relining procedures were performed with auto polymerized addition silicone resilient liner (Softliner®, Promedica, GmbH, Neumünster, Germany) using closed mouth technique ${ }^{(10)}$ (fig. 3).

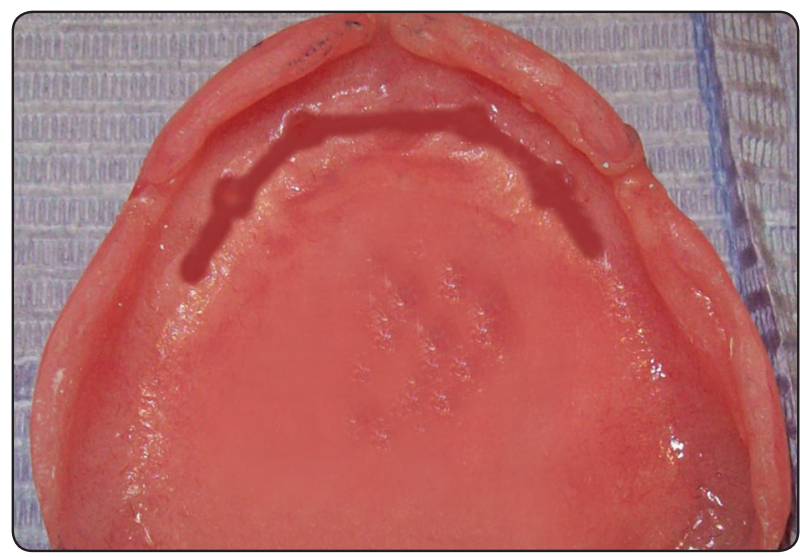

Fig. (3) Soft-liner female housing of bar-implant retained maxillary overdentures.

All prosthetic procedures were performed by the same prosthodontist. All laboratory procedures were completed by the same dental technician under the supervision of the study prosthodontist. The new dentures were delivered to the patients with emphasis on oral hygiene instructions and 3-months regular recall visits for adjustments were scheduled all over the study period.

\section{Evaluation of peri-implant parameters}

In the context of the present study, all patients were recalled and clinically examined at time of overdenture insertion T0, 6 months after overdenture insertion (T6) and 12 months after overdenture insertion (T12). 


\section{Clinical evaluation}

Peri-implant clinical parameters were recorded according to the proposed criteria by Mombelli and coworkers $^{(15)}$ at all 4 implant sites. This included Plaque Index (PI), Bleeding Index (BI), and Gingival Index (GI). Using a calibrated periodontal probe, the distance between marginal border of the gingiva and the tip of the probe was measured and considered as pocket depth (PD). The PI, BI GI, and PD were recorded at lingual, mesial, buccal, and distal aspect of each implant. Implant stability quotient (ISQ) was assessed by resonance frequency analysis (RFA, Osstell TM; Osstell AB, Gothenburg, Sweden) after attaching the SmartPegs to the implant ${ }^{(16,17)}$.

\section{Radiographic evaluation}

Peri-implant bone loss was measured around each implant using a panoramic radiographs ${ }^{(1)}$. The radiographic distance DIB (distance from implant shoulder to first bone contact) (Fig.4) was calculated at mesial and distal sites, according to the method of linear measurements ${ }^{(18)}$. The implant features, with design characteristics of known size, facilitated radiographic measurements of crestal bone level at the proximal sites. The magnification error was calculated from the actual implant lengths. Marginal bone loss (MBL) was calculated by subtracting DIB at $\mathrm{T} 6$ and $\mathrm{T} 12$ from DIB at T0.

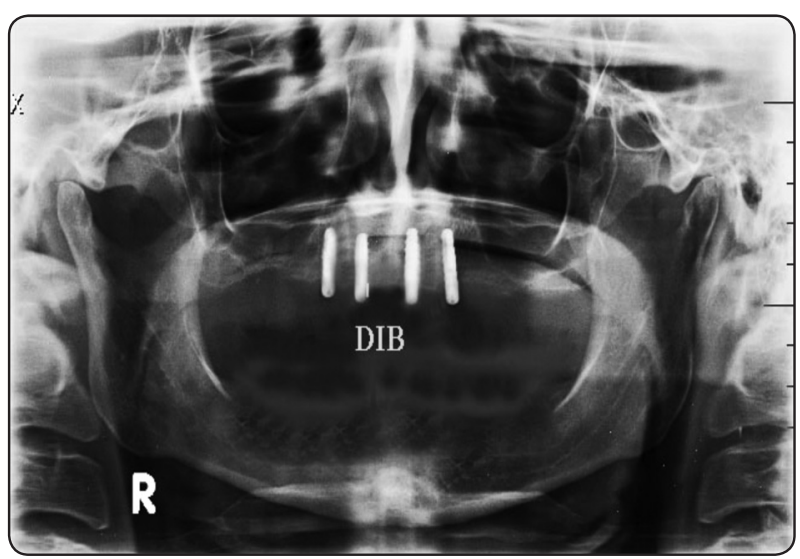

Fig. (4) Evaluation of MBL on panoramic radiographs.
In a pilot exercise, 3 examiners were trained and calibrated to be familiar with measurements, 2 (radiologists) to analyze the radiographs, and 1 (periodontist) to record e the peri-implant parameters. They had to perform all measurements in 6 patients under supervision of the study director (E.D.B). The measurements were evaluated 3 times and differences in measurements were recalculated and adjusted.

\section{Statistical analysis}

The data were analyzed using $\mathrm{SAS}^{\circledR}$ software version 9.2 (SAS Institute, Cary, NC, USA). The data was non parametric as verified by ShapiroWilk Test owing to the small sample size. The reliability of intra- and interpersonal data was tested by $\alpha$ (Cronbach) test. Ordinal variables were expressed as median (minimum-maximum), while continuous variable were presented as mean \pm standard deviation. SAS macro program LD_F1 for non-parametric longitudinal data ${ }^{(19)}$ was used to detect significant differences between observation times. Wilcoxon signed ranks test was used to compare between each two periods. Spearman's rho correlation coefficient was used to assess the relation between radiographic and clinical parameters. $\mathrm{P}$ is significant if $<0.05$ at confidence interval $95 \%$.

\section{RESULTS}

Twenty four implants were inserted for 6 patients who participated in this study. Since the evaluation period was short, all patients completed the clinical and radiographical analysis without drop out. None of the inserted failed after one year followup resulted in $100 \%$ survival rate. Post-insertion adjustments included occlusal refinement, denture base modifications, and replacement of the soft liners if these liners were separated torn or detached from the denture base. Inter examiner reliability of clinical and radiographical measurements was analyzed using Alpha (Cronbach) test. The values of intraclass correlation coefficients (reliability) for all 
parameters were calculated and the measurements were considered reliable if these values $>0.80$.

Peri-implant plaque scores, gingival scores, bleeding scores, probing depths, implant stability and marginal bone loss for the study patients at different observation times (T0, T6 and T12) are presented in table 2 .

There was no significant difference in PI, GI, BI between observation times (Burrner-Langer test, $\mathrm{p}>.05$ ). Both PD and MBL increased significantly with time (Burrner-Langer test, $\mathrm{p}=.05$ ). ISQ decreased significantly at T6 and increased again at T12. Multiple comparison between each 2 observation times are shown in table 2 . There was a significant difference in PD and MBL between T6 and T12. ISQ showed a significant difference between $\mathrm{T} 0$ and $\mathrm{T} 6$, and between $\mathrm{T} 6$ and $\mathrm{T} 12$.

The correlation between clinical parameters (PI, BI, GI, PD and ISQ) and radiographic parameter
(MBL) is presented in table 3. There was a significant positive correlation between MBL and PD only (Spearman correlation, $\mathrm{p}=.001$ ). There was no significant correlation between MBL and other clinical parameters.

TABLE (3) Spearman correlation between periimplant marginal bone loss and other clinical parameters

\begin{tabular}{|c|c|c|}
\hline \multirow{2}{*}{ Plaque index } & \multicolumn{2}{|c|}{ Marginal bone loss } \\
\cline { 2 - 3 } & Correlation coefficient & $\begin{array}{c}\text { P value } \\
(2 \text { tailed })\end{array}$ \\
\cline { 2 - 3 } & -.090 & .163 \\
\hline Gingival index & .066 & .615 \\
\hline Bleeding index & .088 & .741 \\
\hline Probing depth & .208 & $.001 *$ \\
\hline Implant stability & -.117 & .055 \\
\hline
\end{tabular}

*Correlation is significant at the .05 level (2-tailed).

TABLE (2) Clinical and radiographic evaluations at different time intervals

\begin{tabular}{|c|c|c|c|c|}
\hline Parameter & $\begin{array}{c}\text { At time of overdenture } \\
\text { insertion } \\
(\mathrm{T} 0)\end{array}$ & $\begin{array}{c}6 \text { months after } \\
\text { overdenture insertion } \\
\text { (T6) }\end{array}$ & $\begin{array}{c}12 \text { months overdenture } \\
\text { insertion } \\
(\mathrm{T} 2)\end{array}$ & $\begin{array}{c}\text { Burnner -Langer test } \\
\text { (p value) }\end{array}$ \\
\hline $\begin{array}{c}\text { PI } \\
\text { M (Min-Max) }\end{array}$ & 0 & $0(0-1)$ & $0(0-1)$ & 0.157 (NS) \\
\hline $\begin{array}{c}\text { GI } \\
\text { M (Min-Max) }\end{array}$ & $0(0-1)$ & $1(0-1)$ & $0(0-1)$ & $0.321(\mathrm{NS})$ \\
\hline $\begin{array}{c}\mathrm{BI} \\
(\mathrm{Min}-\mathrm{Max})\end{array}$ & $1(0-1)$ & $0(0-1)$ & $0(0-1)$ & 0.147 (NS) \\
\hline $\begin{array}{c}\mathrm{PD}(\mathrm{mm}) \\
(\mathrm{X} \pm \mathrm{SD})\end{array}$ & $1.2 \pm 0.52$ & $1.4 \pm 0.49$ & $1.9 \pm 0.54$ & $.00^{*}$ \\
\hline $\begin{array}{c}\mathrm{ISQ} \\
(\mathrm{X} \pm \mathrm{SD})\end{array}$ & $66.2 \pm 3.4$ & $64.2 \pm 4.1$ & $67.5 \pm 2.9$ & $.034^{*}$ \\
\hline $\begin{array}{c}\mathrm{MBL}(\mathrm{mm}) \\
(\mathrm{X} \pm \mathrm{SD})\end{array}$ & 0 & $1.0 \pm .75$ & $1.5 \pm 0.96$ & $.00^{*}$ \\
\hline
\end{tabular}

$P I=$ plaque index; GI=gingival index; PI=bleeding index; $P D=$ probing depth; ISQ= implant stability quotient; $M B L=$ marginal bone loss. M= median; Min=minimum; Max=maximum; X=mean; SD=Standard deviation; Line connecting values indicating non-significant difference between intervals (Wilcoxon signed ranks test, $p>.05$ ).*p value is significant at .05 level of significance, $N S=$ non-significant 


\section{DISCUSSION}

The denture spaces within the fitting surface around the bar attachments become more evident when the number of implants used to assist the overdentures increases. Therefore, overdentures supported on 4 implants splinted with bars are associated with more denture spaces compared to overdentures supported on 2 implants only to allow ease of insertion and removal of the denture without interference with bars especially if the implants are not placed perpendicular to the ridge as in the anterior maxillary region. These spaces encourage plaque accumulation, pathologic microflora, and peri-implant inflammation $(10,20)$. Direct intraoral technique was used for relining of the overdentures around the bar with soft liners based on the recommendation of other studies $^{(9,10)}$ as it provides intimate contact of denture base with underlying mucosa, registers mucosa under masticatory force, and produces smooth relining surface by contact with oral mucosa. This smooth surface had significantly lower candidal and microbial adhesion compared with rough surface resulting from laboratory processing of resilient liners against dental plaster ${ }^{(21)}$. Silicone soft liners were used as it have been shown that these liners are associated with less microbial colonization than temporary acrylic soft liners. Mutluay et al.(22) founded that candida carriage of silicone soft liners was similar to denture-wearing patients without soft liners. Relief space of $2 \mathrm{~mm}$ thickness was provided by Aluminum foil application on the bar at time of acrylic resin packing to obtain adequate soft liner thickness to achieve its cushion effect ${ }^{(23)}$.

Digital panoramic radiographs were used in evaluation of bone height changes around the implants retaining maxillary overdentures. This technique was also used in many studies to evaluate peri-implant bone loss with maxillary overdentures (1,24). Compared to standardized long-cone paralleling technique, the panoramic radiographs provide several advantages such as simplicity, time saving (all implants are exposed at the same time), reduction of radiation dose to the patient, reduction of the errors resulted from positioning intra-oral film holders, and possibility to depict the entire implant on the radiograph ${ }^{(25)}$. The digital panoramic images facilitate the quantifcation of bone changes. ${ }^{(25,26)}$. The inherent problem of magnification in these radiographs can be computed reliably by comparing the radiologic implant length with the actual implant length relative to a reference point ${ }^{(27)}$. Positioning of the intraoral film perpendicular to the long cone of the x-ray machine and parallel to the implant long axis (which is required for long cone paralleling technique) is usually not possible in the anterior region of the maxilla due to the slope of the palate and the inclination of the implants. Zechner et al. (27) concluded that peri-apical and panoramic imaging techniques are comparable clinically in terms of the precision with which they could be used to measure marginal bone loss.

The survival rate of the implants after one year was $100 \%$. This rate was higher than the survival rate obtained by Mersicke-stern et al. ${ }^{(1)}$ for maxillary overdentures supported by 4 implants and retained by bar and metal clips after 5 years. The difference in survival rate may be due to the short follow-up period in this study. Another reason may be attributed to the soft liner attachments used in this study which absorb forces ${ }^{(8,12)}$ and decreases stresses transmitted to the implants after loading. In contrast metal clips may increase forces transmitted to the implants after loading with overdentures which may led to early implant failure.

There was no significant difference in PI, GI, BI between observation times. This could be attributed to the soft liner attachment which completely obturates space around the bar and partially obturates space under the bar ${ }^{(8)}$, thereby it minimizes plaque and microbial adhesion that cause peri-implant 
tissue inflammation ${ }^{(8)}$. These liners continuously clean the bar and the abutments during denture insertion and removal thus may prevent plaque accumulation in the sheltered areas around the bar and prevent gingival hyperplasia ${ }^{(10)}$. A similar observation was noted by Elsyad and associates ${ }^{(10)}$ who found that resilient liner attachment had significantly decreased plaque scores, gingival scores with advance of time when compared with clip attachment for bar-implant retained mandibular overdentures. Both PD increased significantly with time. A similar observation was also noted for 4-implant supported maxillary overdentures with bar and metal clip attachments ${ }^{(1)}$. This could be attributed to the increased marginal bone loss with time.

MBL was $1.5 \mathrm{~mm}$ after one year. A similar observation was noted by Adell and coworkers, ${ }^{(28)}$ who reported bone loss of 1.3 to $1.5 \mathrm{~mm}$ was measured around maxillary implants in the anterior zone, covering a time period from the healing phase through the first year of loading. However, this amount was lower than marginal bone resorption obtained by Zitzmann \& Marinello(29) for conventially loaded implants by maxillary overdentures after a similar observation period. The decreased amount of bone loss may be due to the soft liners absorb and distribute masticatory forces to the implants and edentulous ridge, thus provide greater latitude of movement which in turn increases patient comfort ${ }^{(8,12)}$. The resilient liner attachment allows vertical, lateral and rotational movement of the overdentures, makes the overdentures mucosal supported and reduces stress applied to the implants which in turn reduces peri-implant bone.

$$
\text { Resonance frequency analysis }
$$
measurements have been used to document changes during healing of the implant-bone interface ${ }^{(30,31)}$. An increase in ISQ is related to an increase in the stiffness of the interface between the implant and the surrounding bone ${ }^{(16)}$. ISQ decreased significantly at T6 and increased again at T12. The high ISQ values obtained may the shock absorbing capability of the resilient liner which reduce stresses to the implant and minimize peri-implant bone loss as stated earlier. This increase bone-to-implant contact and enhance rigid anchorage of implants in bone. Therefore soft liners may have significant clinical implications in terms of accelerated bone healing and increase implant stability in areas of poor quality bone ${ }^{(32)}$ especially when immediate implant loading was used.

There was a significant positive correlation between MBL and PD. In line with this observation, Quirynen et al.(33) reported positive correlations between bone levels recorded on radiographs and the extent of peri-implant probe penetration. The other clinical parameters showed no-correlation with MBL. This concurs with the findings of another study conducted on implant supported maxillary overdentures with bar/clip attachments who noted a non-significant correlation between clinical parameters and crestal bone loss ${ }^{(1)}$. This suggest that these parameters are of limited clinical value in assessing and predicting future peri-implant bone $\operatorname{loss}^{(34)}$.

\section{CONCLUSION}

Soft liner attachments for cantilevered barimplant retained maxillary overdentuers are associated with good peri-implant soft tissue health, good implant stability and minimal marginal bone loss after one year. However, long term randomized controlled clinical trials are needed to compare the clinical and radiographic out-come of this treatment modality with conventional clips used for bar attachments.

\section{REFERENCES}

1. Mericske-Stern R, Oetterli M, Kiener P, Mericske E. A follow-up study of maxillary implants supporting an overdenture: clinical and radiographic results. Int J Oral Maxillofac Implants. 2002;17(5):678-686. 
2. Mericske-Stern RD, Taylor TD, Belser U. Management of the edentulous patient. Clin Oral Implants Res. 2000;11 Suppl 1:108-125.

3. Carlson B, Carlsson GE. Prosthodontic complications in osseointegrated dental implant treatment. Int J Oral Maxillofac Implants. 1994;9(1):90-94.

4. Akca K, Akkocaoglu M, Comert A, Tekdemir I, Cehreli MC. Human ex vivo bone tissue strains around immediately loaded implants supporting maxillary overdentures. Clin Oral Implants Res. 2005;16(6):715-722.

5. Barao VA, Assuncao WG, Tabata LF, de Sousa EA, Rocha EP. Effect of different mucosa thickness and resiliency on stress distribution of implant-retained overdentures-2D FEA. Computer methods and programs in biomedicine. 2008;92(2):213-223.

6. Misch CE. Treatment Options for Mandibular Implant Overdentures in: Misch CE, Bidez MW, Judy KWM et al, eds Dental implant prosthetics. 3nd ed St Louis: Mosby. 2005:P.218-235.

7. Sadowsky SJ. Treatment considerations for maxillary implant overdentures: a systematic review. J Prosthet Dent. 2007;97(6):340-348.

8. Adrian ED, Krantz WA, Ivanhoe JR. The use of processed silicone to retain the implant-supported tissue-borne overdenture. J Prosthet Dent. 1992;67(2):219-222.

9. ELsyad MA. Prosthetic aspects and patient satisfaction with resilient liner and clip attachments for bar- and implant-retained mandibular overdentures: a 3-year randomized clinical study. Int J Prosthodont. 2012;25(2):148-156.

10. Elsyad MA, Shoukouki AH. Resilient liner vs. clip attachment effect on peri-implant tissues of bar-implant-retained mandibular overdenture: a 1-year clinical and radiographical study. Clin Oral Implants Res. 2010;21(5):473-480.

11. Elsyad MA, Ashmawy TM, Faramawy AG. The influence of resilient liner and clip attachments for bar-implantretained mandibular overdentures on opposing maxillary ridge. A 5-year randomised clinical trial. J Oral Rehabil. 2014;41(1):69-77.

12. Kiat-Amnuay S, Khan Z, Gettleman L. Overdenture retention of four resilient liners over an implant bar. J Prosthet Dent. 1999;81(5):568-573.

13. Shaygan F, Z. K, L. G. Retention and longevity of resilient denture liners in implant overdentures. Journal of Dental Research. 1993;72:272.
14. Elsyad MA, Al-Mahdy YF, Salloum MG, Elsaih EA. The effect of cantilevered bar length on strain around two implants supporting a mandibular overdenture. Int J Oral Maxillofac Implants. 2013;28(3):e143-150.

15. Mombelli A, van Oosten MA, Schurch E, Jr., Land NP. The microbiota associated with successful or failing osseointegrated titanium implants. Oral Microbiol Immunol. 1987;2(4):145-151.

16. Meredith N, Alleyne D, Cawley P. Quantitative determination of the stability of the implant-tissue interface using resonance frequency analysis. Clin Oral Implants Res. 1996;7(3):261-267.

17. Glauser R, Sennerby L, Meredith N, Ree A, Lundgren A, Gottlow J, et al. Resonance frequency analysis of implants subjected to immediate or early functional occlusal loading. Successful vs. failing implants. Clin Oral Implants Res. 2004;15(4):428-434.

18. Bragger U, Hafeli U, Huber B, Hammerle CH, Lang NP. Evaluation of postsurgical crestal bone levels adjacent to non-submerged dental implants. Clin Oral Implants Res. 1998;9(4):218-224.

19. Brunner E, Langer F. Nichparametrische Analyse longitudinaler Daten. M ünchen: R. Oldenbourg Verlag 1999.

20. Lachmann S, Kimmerle-Muller E, Gehring K, Axmann D, Gomez-Roman G, Watzek G, et al. A comparison of implant-supported, bar- or ball-retained mandibular overdentures: a retrospective clinical, microbiologic, and immunologic study of 10 edentulous patients attending a recall visit. Int J Prosthodont. 2007;20(1):37-42.

21. Nevzatoglu EU, Ozcan M, Kulak-Ozkan Y, Kadir T. Adherence of Candida albicans to denture base acrylics and silicone-based resilient liner materials with different surface finishes. Clin Oral Investig. 2007;11(3):231-236.

22. Mutluay MM, Oguz S, Orstavik D, Floystrand F, Dogan A, Soderling E, et al. Experiments on in vivo biofilm formation and in vitro adhesion of Candida species on polysiloxane liners. Gerodontology. 2010;27(4):283-291.

23. Kawano F, Asaoka K, Nagao K, Matsumoto N. Effect of viscoelastic deformation of soft tissue on stresses in the structures under complete denture. Dental materials journal. 1990;9(1):70-79.

24. Troeltzsch M, Troeltzsch V, Brodine AH, Frankenberger R, Messlinger K, Troeltzsch M. Clinical performance and peri-implant parameters of 132 implants supporting loca- 
tor-retained overdentures: a case series of 33 patients. Int J Oral Maxillofac Implants. 2013;28(4):1132-1139.

25. Batenburg RH, Meijer HJ, Geraets WG, van der Stelt PF. Radiographic assessment of changes in marginal bone around endosseous implants supporting mandibular overdentures. Dento maxillo facial radiology. 1998;27(4):221224.

26. Mericske-Stern R, Steinlin Schaffner T, Marti P, Geering AH. Peri-implant mucosal aspects of ITI implants supporting overdentures. A five-year longitudinal study. Clin Oral Implants Res. 1994;5(1):9-18.

27. Zechner W, Watzak G, Gahleitner A, Busenlechner D, Tepper G, Watzek G. Rotational panoramic versus intraoral rectangular radiographs for evaluation of peri-implant bone loss in the anterior atrophic mandible. Int J Oral Maxillofac Implants. 2003;18(6):873-878.

28. Adell R, Lekholm U, Rockler B, Branemark PI. A 15-year study of osseointegrated implants in the treatment of the edentulous jaw. Int J Oral Surg. 1981;10(6):387-416.

29. Zitzmann NU, Marinello CP. Treatment outcomes of fixed or removable implant-supported prostheses in the edentulous maxilla. Part II: clinical findings. J Prosthet Dent. 2000;83(4):434-442.
30. Barewal RM, Oates TW, Meredith N, Cochran DL. Resonance frequency measurement of implant stability in vivo on implants with a sandblasted and acid-etched surface. Int J Oral Maxillofac Implants. 2003;18(5):641-651.

31. Friberg B, Sennerby L, Linden B, Grondahl K, Lekholm U. Stability measurements of one-stage Branemark implants during healing in mandibles. A clinical resonance frequency analysis study. Int J Oral Maxillofac Surg. 1999;28(4):266-272.

32. Goene RJ, Testori T, Trisi P. Influence of a nanometerscale surface enhancement on de novo bone formation on titanium implants: a histomorphometric study in human maxillae. Int J Periodontics Restorative Dent. 2007;27(3): 211-219.

33. Quirynen M, van Steenberghe D, Jacobs R, Schotte A, Darius P. The reliability of pocket probing around screwtype implants. Clin Oral Implants Res. 1991;2(4):186-192.

34. Elsyad MA, Al-Mahdy YF, Fouad MM. Marginal bone loss adjacent to conventional and immediate loaded two implants supporting a ball-retained mandibular overdenture: a 3-year randomized clinical trial. Clin Oral Implants Res. 2012;23(4):496-503. 